УДК $615.32 / .31$

\title{
ОПРЕДЕЛЕНИЕ ФЕНОЛЬНЫХ КИСЛОТ В РАСТЕНИЯХ МЕТОДОМ ВЭЖХ
}

\author{
() Д.В. Моисеев
}

Витебский государственный медицинский универсuтет, пр. Фрунзе, 27,
Витебск, 210023, (Республика Беларусь), e-mail: ussr80@yandex.ru

Представлены коэффициенты емкости 15 фенольных кислот (метод ВЭЖХ) с использованием следующих хроматографических условий: аналитические колонки Zorbax SB 250×4,6 мм, 5 мкм с сорбентами C-18, C-8, Phenyl; подвижная фаза 0,01 М дигидрофосфат калия ( $\mathrm{pH}=3,0)$ и ацетонитрил в соотношении $85: 15$ (по объему); температура колонки $30{ }^{\circ} \mathrm{C}$; описаны спектры поглощения при длинах волн 200-400 нм. Приведенную хроматографическую систему предлагается использовать для предварительной идентификации фенольных соединений в растительных объектах.

Ключевые слова: фенольные кислоты, ВЭЖХ, кофейная кислота, хлорогеновая кислота.

\section{Введение}

Фенольные кислоты - большая группа биологически активных веществ, относящихся к многочисленной группе фенольных производных. Интерес к этой группе соединений объясняется большим диапазоном их биологического действия, широким распространением в природе, и они относятся к классам практически нетоксичных или относительно безвредных веществ $[1,2]$. Большинство фенольных соединений являются антиоксидантами за счет связывания свободных радикалов и ионов тяжелых металлов.

Фенольные кислоты растительного происхождения классифицируются на производные оксибензойной кислоты ( $n$-оксибензоная, протокахетовая, ванилиновая, галловая и сиреневая) и производные оксикоричной кислоты ( $n$-кумаровая, кофейная, ферруловая и синаповая). Кроме них в растениях часто встречаются сложные эфиры оксикоричных и гидроароматических кислот (хлорогеновая кислота) и полимерные фенольные соединения (эллаговая кислота). Биосинтез производных коричной кислоты из ароматических аминокислот представлен на рисунке.

Выделение из растений. Для выделения суммы фенольных кислот из растений чаще всего используют экстракцию водно-спиртовыми или водно-метанольными смесями растворителей. Полученные извлечения упаривают, разбавляют горячей водой и удаляют липофильные вещества (жирные масла, смолы, хлорофилл) из водной фазы в делительной воронке хлороформом, дихлорэтаном или четыреххлористым углеродом.

Индивидуальные соединения выделяют, используя колоночную хроматографию с полиамидными, силикагельными или целлюлозными сорбентами. Элюирование веществ с колонки обычно проводят этанолом с возрастающей концентрацией спиртов или спирто-водными смесями, начиная с воды и ступенчато увеличивая концентрацию спирта.

Идентификация фенольных кислот. Для идентификации фенольных кислот можно использовать их физико-химические свойства: определение температуры плавления, определение удельного вращения оптических изомеров, а также сравнение их УФ-, ИК-, ПМР-спектров со спектрами стандартных образцов. Однако данные методы требуют высокой степени очистки исследуемых образцов веществ и поэтому дороги и трудоемки. Оптимальным методом по стоимости и трудоемкости анализов для идентификации фенольных кислот в новом растительном сырье являются хроматографические методы (ВЭЖХ и ТСХ). С точки зрения получения данных о химической структуре веществ в растениях наиболее информативным

Моисеев Дмитрий Владимирович - кандидат фармацевтических наук, доцент, заведующий кафедрой стандартизации лекарственных средств, e-mail: ussr80@yandex.ru. вариантом детектирования в ВЭЖХ является последовательное применение фотодиодноматричного и массспектрометрического детекторов. Для облегчения проведения комплекса работ по идентификации БАВ растительного происхождения создаются хромато- 


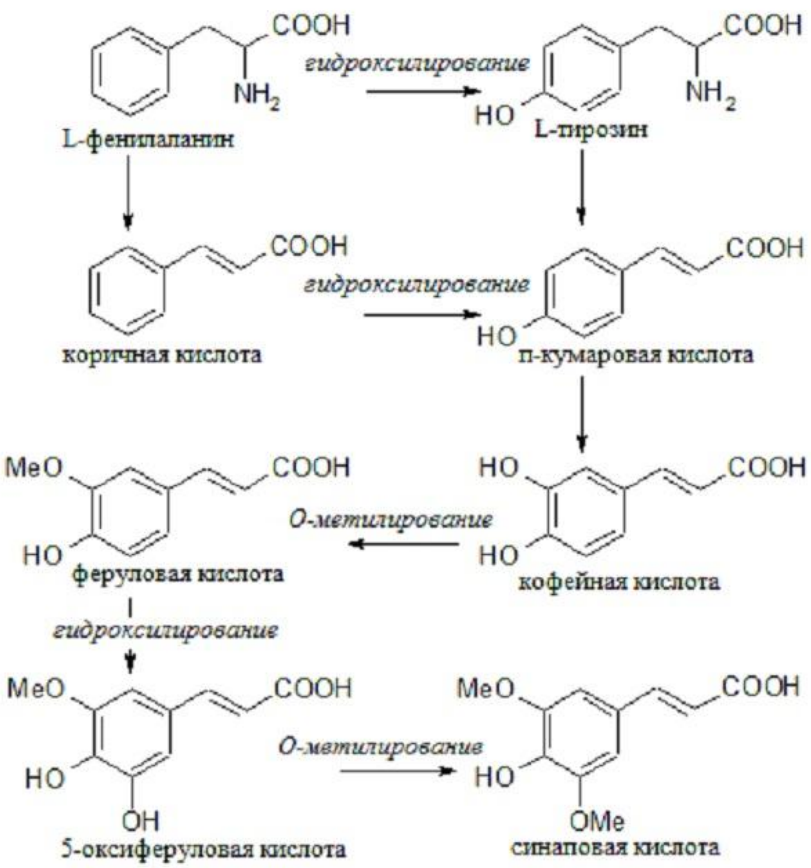

Схема биосинтеза производных коричной кислоты в растениях (Ме - метильный радикал) [2] графические химико-аналитические библиотеки веществ, представляющие собой хроматограммы и спектральные характеристики (спектры в инфракрасной, ультрафиолетовой и видимой областях света и масс-спектры) веществ, записанные в определенных стандартизированных хроматографических условиях. Следует заметить, что для веществ, относящихся к токсическим, подобные базы активно используются. В них указываются коэффициенты емкости, определенные в нескольких различных доступных хроматографических системах (при использовании разных колонок или систем растворителей). Например, в справочнике Clarke's Analysis of Drugs and Poisons [3] приводится свыше 20 различных стандартных систем растворителей для метода ТСХ и более 15 хроматографических систем для метода ВЭЖХ. Обычно для идентификации веществ, относящихся к одной группе (например, антидепрессанты), при-

водятся коэффициенты удерживания в 2-3 различных хроматографических системах, которые подбираются индивидуально исследователями. Из веществ растительного происхождения в данный справочник включены данные о наркотических веществах (опиаты, каннабиоиды, кокаин), сердечные гликозиды и некоторые индивидуальные алкалоиды. Ранее мы представляли подобную базу для флавоноидов [4]. В настоящей статье представлены подобные исследования для фенольных кислот.

\section{Экспериментальная часть}

В научной литературе приводится множество различных методик определения фенольных соединений в растениях методом ВЭЖХ. Главные недостатки большинства из них: во-первых, в статьях указываются времена удерживания веществ, а не коэффициенты емкости; во-вторых, условия хроматографического анализа одних и тех же объектов значительно различаются.

Названия веществ приведены в соответствии с химической структурой. Чистота стандартных образцов, определенная методом ВЭЖХ, составляла более $99 \%$.

Работа выполнялась на жидкостном хроматографе фирмы Agilent HP 1100, в комплекте с системой подачи и дегазации на четыре растворителя G1311A, диодно-матричным детектором G1315B, термостатом колонок G1316A, устройством для автоматического ввода образцов (автосэмплер) G1313А. Сбор данных, обработка хроматограмм и спектров поглощения проводилась с помощью программы Agilent ChemStation for LC 3D. При выборе систем растворителей основной посылкой стало то, что время проведения одного предварительного анализа растительного объекта не должно превышать 2 ч (коэффициенты емкости веществ менее 50) и режим элюирования должен быть изократическим (т.е. состав подвижной фазы не должен изменяться в течение анализа) [5, 6]. Хроматографические колонки подбирались по принципу различной полярности (хроматографические колонки Zorbax SB с сорбентами Phenyl, C-18, C-8, зернение - 5 мкм, длина колонки 250 мм, диаметр - 4,6 мм, производитель Agilent Technologies). Система растворителей: 0,01 М дигидрофосфат калия, доведенны до значения $\mathrm{pH}=3,0$ концентрированной фосфорной кислотой и ацетонитрил (исследовали разные объемные соотношения, оптимальное соотношение 85 :15 по объему), температура колонки 30 ㄷ․ В максимумах пиков были сняты спектры поглощения при длинах волн 200-400 нм, шаг 1 нм.

Далее рассчитывали коэффициенты емкости по формуле: $\mathrm{k}^{\prime}=\left(\mathrm{t}-\mathrm{t}_{0}\right) / \mathrm{t}_{0}$, где $\mathrm{t}-$ время удерживания вещества, $\mathrm{t}_{0}$ - мертвое время колонки (определяется по времени удерживания несорбируемого компонента нитрит натрия, $\lambda=210$ нм). Полученные данные представлены в таблице. 
Коэффициенты емкости фенольных кислот на хроматографических колонках с различными сорбентами

\begin{tabular}{|c|c|c|c|c|}
\hline \multirow[t]{2}{*}{ Вещества (химические названия), CAS number } & \multicolumn{3}{|c|}{$\begin{array}{l}\text { Коэффициенты удержи- } \\
\text { вания на различных сор- } \\
\text { бентах }\end{array}$} & \multirow{2}{*}{$\begin{array}{c}\text { Максимумы поглощения в } \\
\text { ультрафиолетовом спектре } \\
\text { (спектры записаны } \\
\text { в подвижной фазе) }\end{array}$} \\
\hline & $\mathrm{C}-8$ & $\mathrm{C}-18$ & Phenyl & \\
\hline \multicolumn{5}{|c|}{ Производные оксибензойной кислоты } \\
\hline 2,5-дигидроксибензойная кислота, CAS [490-79-9] & 1,56 & 1,74 & 1,43 & 210, 326, плечо 198, плечо 234 \\
\hline $\begin{array}{l}\text { 3,4-дигидроксибензойная кислота (протокатеховая ки- } \\
\text { слота), CAS [99-50-3] }\end{array}$ & 1,03 & 0,97 & 0,98 & $208,218,260,294$ \\
\hline $\begin{array}{l}\text { 4-гидрокси-3-метокси-бензойная кислота (ванилиновая), } \\
\text { CAS [121-34-6] }\end{array}$ & 2,74 & 2,57 & 2,49 & $205,218,260,292$ \\
\hline бензойная кислота, CAS [65-85-0] & 8,51 & 10,64 & 5,52 & $194,230,274$ \\
\hline 4-гидроксибензойная кислота, CAS [99-96-7] & 2,33 & 2,13 & 2,06 & 196, 256, плечо 210 \\
\hline $\begin{array}{l}\text { 4-гидрокси-3,5-диметокси-бензойная кислота (сиреневая } \\
\text { кислота), CAS [530-57-4] }\end{array}$ & 1,12 & 2,63 & 1,15 & 218,276 \\
\hline $\begin{array}{l}\text { 3,4,5-тригидрокси-бензойная кислота (галловая кисло- } \\
\text { та), CAS [149-91-7] }\end{array}$ & 0,39 & 0,35 & 0,42 & 214,272 \\
\hline \multicolumn{5}{|c|}{ Производные оксикоричной кислоты } \\
\hline $\begin{array}{l}\text { 3,4-дигидроксикоричная кислота (кофейная кислота), } \\
\text { CAS [331-39-5] }\end{array}$ & 2,63 & 2,46 & 2,51 & 218, 240, 324, плечо 298 \\
\hline $\begin{array}{l}\text { Хлорогеновая кислота (3-кофеоиловый эфир хинной } \\
\text { кислоты), CAS [327-97-9] }\end{array}$ & 1,15 & 1,09 & 1,36 & 218,242, 326, плечо 297 \\
\hline Циннамовая кислота (коричная кислота), CAS [470-37-1] & 25,03 & 34,69 & 15,57 & $204,216,278$ \\
\hline $\begin{array}{l}\text { 4-гидроксикоричная кислота (пара-кумаровая кислота), } \\
\text { CAS [501-98-4] }\end{array}$ & 5,97 & 5,43 & 5,25 & 210, 226, 310, плечо 295 \\
\hline $\begin{array}{l}\text { транс-4-гидрокси 3-метоксикоричная кислота (феруло- } \\
\text { вая кислота), CAS [1135-24-6] }\end{array}$ & 7,21 & 6,91 & 6,48 & $218,236,324$, плечо 295 \\
\hline $\begin{array}{l}\text { транс-3,5-диметокси-4-гидроксикоричная кислота (си- } \\
\text { наповая кислота), CAS [530-59-6] }\end{array}$ & 7,40 & 7,01 & 7,18 & 194, 238, 324, плечо 226 \\
\hline $\begin{array}{l}\text { орто-кумаровая кислота (2-гидроксикоричная кислота), } \\
\text { CAS [614-60-8] }\end{array}$ & 11,06 & 13,06 & 8,07 & 192, 213, 276, 324, плечо 226 \\
\hline \multicolumn{5}{|c|}{ Другие кислоты } \\
\hline Эллаговая кислота, CAS [476-66-4] & 5,16 & 6,72 & 7,85 & $\begin{array}{l}\text { 199, 254, 367, плечо } 305, \\
\text { плечо } 354\end{array}$ \\
\hline
\end{tabular}

Как следует из таблицы, с увеличением количества гидроксильных групп в молекулах кислот происходит снижение коэффициентов емкости (зависимость хорошо прослеживается в ряду: галловая, протокатеховая, 4-гидроксибензойная и бензойная кислоты). Для кислот, имеющих в структуре несколько функциональных групп, коэффициенты емкости для всех трех исследованных сорбентов практически не различаются. Для бензойной и коричной, а также орто-гидроксикоричной (гидроксильная группа пространственно экранирована карбоксильной) кислот характерно увеличение коэффициентов емкости в ряду сорбентов Phenyl, C-8 и C-18.

Предлагаемые условия хроматографирования не являются окончательными и оптимальными, а служат только для предварительной качественной оценки содержащихся фенольных кислот в растениях. В зависимости от преобладающей группы соединений в экстракте исследуемого растения хроматограмму можно «растянуть» - уменьшить содержание ацетонитрила (для гидрофильных соединений) или «сжать» увеличить содержание ацетонитрила, соответственно.

Следует помнить, что при работе с колонками различных фирм-производителей, например, Waters Spherisorb ODS-2 C-18 и Agilent Zorbax SB C-18, коэффициенты емкости соединений могут незначительно различаться. Это связано с особенностями технологии производства сорбента (содержание углерода в неподвижной фазе, площадь поверхности сорбента, форма силикагеля, степень прививки активных групп, наличие эндкеппинга и др.), а также со степенью изношенности колонки. Однако механизм разделения веществ, близких по химической структуре, на хроматографических колонках различных производителей будет одинаков.

Для проверки правильности коэффициентов емкости рекомендуется использовать относительные коэффициенты емкости (т.е. по сути, селективность разделения ( $\alpha$ ) идентифицируемого вещества и какогонибудь общедоступного стандарта, например, кофейной кислоты). Селективность разделения $\left(\alpha=\mathrm{k}_{? ? ? ?}^{\prime} / \mathrm{k}_{\text {станд. }}\right.$ ) будет практически неизменна при незначительном изменении условий хроматографирования, что связано с одинаковым механизмом разделения. 


\section{Выводы}

Нами предложена и апробирована на 15 веществах хроматографическая система, позволяющая за короткий промежуток времени провести предварительные исследования по идентификации фенольных кислот в растительных объектах. Разделение предлагается проводить в подвижной фазе $(0,01$ М дигидрофосфат калия, доведенной до значения $\mathrm{pH}=3,0$ концентрированной фосфорной кислотой и ацетонитрил 85 : 15 по объему), однако ее окончательный ее состав формируется в соответствии с целью анализа.

\section{Список литературы}

1. Соколов С.Я. Фитотерапия и фитофармакология: Руководство для врачей. М., 2000. 976 с.

2. Муравьева Д.А. Фармакогнозия. М., 1978. 656 с.

3. Galichet L.Y., Watts Jo. Clarke's Analysis of Drugs and Poisons in pharmaceuticals, body fluids and postmortem material: Fourth Edition. London, 2011. 2473 p.

4. Моисеев Д.В., Шелюто В.Л., Бузук Г.Н. Идентификация флавоноидов в растениях методом ВЭЖХ // Химикофармацевтический журнал. 2011. №1. С. 35-38.

5. Рудаков О.Б., Востров И.А., Федоров С.В., Филиппов А.А., Селеменев В.Ф., Приданцев А.А. Спутник хроматографиста. Методы жидкостной хроматографии / под ред. В.Ф. Селеменева. Воронеж, 2004. 528 с.

6. Шатц В.Д., Сахартова О.В. Высокоэффективная жидкостная хроматография. Рига, 1988. 390 с.

Поступило в редакиию 15 декабря 2013 г.

\section{Moiseev D.V. DETERMINATION OF PHENOLIC ACIDS IN PLANTS BY HPLC}

Vitebsk State Medical University, pr. Frunze, 27, Vitebsk, 210023, (Republic of Belarus), e-mail: ussr80@yandex.ru

Factors of capacities of 15 phenolic acid (HPLC-method) with use following chromatographic conditions are presented: analytical columns Zorbax SB $250 \times 4,6 \mathrm{~mm}, 5$ microns with sorbents C-18, C-8, Phenyl; a mobile phase 0,01 M potassium dihydrophosphate $(\mathrm{pH}=3,0)$ and acetonitrile in the ratio $85: 15(\mathrm{v} / \mathrm{v})$; column temperature $30^{\circ} \mathrm{C}$; absorption spectra are described at lengths of waves of $200-400 \mathrm{~nm}$. Presented chromatographic system are offered to be used for preliminary identification of phenolic compounds in plants.

Keywords: phenolic acids, HPLC, caffeic acid, chlorogenic acid.

\section{References}

1. Sokolov S.Ja. Fitoterapija i fitofarmakologija: Rukovodstvo dlja vrachej. [Phytotherapy and phytopharmacology: A Guide for Physicians.]. Moscow, 2000, 976 p. (in Russ.).

2. Murav'eva D.A. Farmakognozija. [Pharmacognosy]. Moscow, 1978, 656 p. (in Russ.).

3. Galichet L.Y., Watts Jo. Clarke's Analysis of Drugs and Poisons in pharmaceuticals, body fluids and postmortem material: Fourth Edition. London, 2011, 2473 p.

4. Moiseev D.V., Sheljuto V.L., Buzuk G.N. Himiko-farmacevticheskij zhurnal, 2011, no. 1, pp. 35-38. (in Russ.).

5. Rudakov O.B., Vostrov I.A., Fedorov S.V., Filippov A.A., Selemenev V.F., Pridancev A.A. Sputnik hromatografista. Metody zhidkostnoj hromatografii. [Satellite hromatografista. Liquid chromatography Methods]. Voronezh, 2004, 528 p. (in Russ.).

6. Shatc V.D., Sahartova O.V. Vysokojeffektivnaja zhidkostnaja hromatografija. [High performance liquid chromatography]. Riga, 1988, 390 p. (in Russ.). 